\title{
Prospective, Randomized, Double-Blind, Placebo- Controlled Study on Efficacy of Copaiba Oil in Silicone-Based Gel to Reduce Scar Formation
}

Jill Waibel $\cdot$ Harshad Patel $\cdot$ Erica Cull $\cdot$ Raman Sidhu •

Rodrigo Lupatini (D)

Received: September 14, 2021 / Accepted: October 13, 2021 / Published online: October 23, 2021

(C) The Author(s) 2021

\begin{abstract}
Introduction: Scars are the end result of a biologic and natural process of wound repair after injury, surgery, acne, illness, burns, and infection. When skin is damaged, a fast and coordinated body response is triggered by four highly integrated and overlapping phases including homeostasis, inflammation, proliferation, and tissue remodeling. Healing of a skin wound may result in an abnormal scar if the balance among these four phases is lost during the healing process. Various topical treatments have been used for their ability to reduce unsightly scar formation. Recently, studies have shown improvement in scar appearance after treating with silicone gels containing natural herbal ingredients. The aim of this study is to evaluate the efficacy of a novel silicone-based gel containing copaiba oil (Copaderm) for prevention and/or appearance reduction of different types of abnormal scars.
\end{abstract}

Methods: This study was designed as a prospective, randomized, double-blind, placebo-controlled trial involving 42 patients with

J. Waibel

Miami Dermatology \& Laser Research Institute, 7800 SW 87th Avenue, Suite B-200, Miami, USA

H. Patel · E. Cull · R. Sidhu · R. Lupatini $(\bowtie)$

Medisca Pharmaceutique Inc., 6090 Henri Bourassa

West, Montreal H4R3A6, Canada

e-mail: rlupatini@medisca.com abnormal scars, divided into two groups. Each group received either a topical scar formulation consisting of copaiba oil in silicone gel or a placebo gel twice a day for 84 days. Assessments of the scars were performed at 0,28 , and 84 days following the onset of topical application using three methods: a clinical assessment using the Manchester Scar Scale, a photographic assessment to establish before and after treatment improvements, and at the end of the study period, patients completed a final satisfaction questionnaire.

Results: Of the original 42 patients, 32 completed the evaluation. There was a significant difference with respect to the overall score of the Manchester Scar Scale between the two groups from baseline to 84 days $(P<0.05)$. All patients with copaiba oil in silicone gel achieved improvement of their scars, based on overall score at 84 days. A visible scar reduction was observed with photographic assessment. Eighty-nine percent of subjects $(n=16)$ with copaiba oil in silicone gel rated as being satisfied or very satisfied after 84 days of treatment.

Conclusion: Our findings support the hypothesis that copaiba oil in silicone-derivative gel was able obtain significant improvement in color, contour, distortion, and texture for different types of scar through the Manchester Scar Scale analysis. These findings contribute to reducing abnormal scar formation during the healing process. 
Keywords: Abnormal scar; Copaderm; Copaiba oil; Manchester Scar Scale; Scar reduction; Silicone gel

\section{Key Summary Points}

\section{Why carry out this study?}

The association of natural ingredients with silicone-based gels has been shown to be effective in topical therapy for abnormal scar reduction

The current clinical trial evaluated the effectiveness of Copaiba oil associated with silicone gel in reducing the appearance of different types of scars

\section{What was learned from the study?}

Copaiba oil in silicone-derivative gel (Copaderm) improves the scarring outcome of abnormal scars and provides a beneficial effect on the scar appearance

The color, contour, distortion, and texture of the scars reduce over time with Copaderm applied twice a day over 84 days

\section{INTRODUCTION}

The wound healing process after injury to the skin is complex, with many overlapping mechanisms involved, including inflammation, proliferation, and tissue remodeling. Scars arise after almost every dermal injury. The formation of a scar is a natural and inevitable outcome of mammalian tissue repair that usually forms and becomes visible during the remodeling phase of wound healing [1]. Estimates indicate that each year around 100 million people in the developed world acquire scars following elective surgery and surgery for trauma, with approximately $15 \%$ of these cases developing abnormal or unesthetic scars. Excessive scarring can have profound physical, psychological, esthetic, and social consequences. Some of these problems include itching, stiffness, scar contractures, and pain as physical outcomes, and anxiety, mood disturbance, diminished self-esteem, and social ostracism leading to isolation and reduced engagement in society as social and psychological consequences [2, 3].

Various topical treatments have been used for their ability to reduce scar formation [4]. Occlusive dressings containing silicones have successfully been employed as first-line treatment in the prevention of a wide range of scars. Silicone-based products have important advantages compared with other scar reduction therapies as they are a painless non-invasive treatment, have a strong patient compliance, and are easy to apply. Furthermore, siliconebased gels are cosmetically acceptable and exert several beneficial actions for injured skin such as hydration of the stratum corneum, antimicrobial protection, homeostasis of the skin's barrier, and control the synthesis and deposition of collagen during the remodeling phase of skin healing. Recently, studies have shown improvement in scar appearance after treatment with silicone gels containing natural herbal ingredients $[5,6]$.

In this context, natural products such as plant extracts and essential oils have been beneficial in the development of new products for scar treatment, mainly due to their emollient, moisturizing, antimicrobial, and anti-inflammatory activities [7]. Among the medicinal plants with potential efficacy for improving scar appearance is copaiba oil, an oil rich in terpenic compounds obtained by tapping the trunk of the trees from different species of Copaifera $\mathrm{L}$. [8]. Copaiba oil is used in Amazonian traditional medicine, especially as an anti-inflammatory and antimicrobial ingredient for wound healing, and its use has been reported since the sixteenth century [9]. In addition to its application in traditional medicine, studies have demonstrated that copaiba oil is effective in collagen formation and increasing elastic fibers during the healing process. Copaiba oil was also able to increase the concentration of fibroblast and blood vessels of postoperative wounds, demonstrating an improvement of tissue repair after topical application. These findings suggested copaiba oil as a promising adjuvant in 
topical formulations for wound healing, justifying its traditional use [10-14].

However, no study has tested the efficacy of topical copaiba oil in a silicone-based gel to improve the appearance of scars. This is of particular interest because of the potential complementary and synergistic effects of copaiba oil and silicone in scar reduction. The objective of this 84-day, randomized, double-blind, placebocontrolled study was to evaluate the efficacy of a novel silicone-based gel containing copaiba oil for prevention and/or reduction in appearance of different types of abnormal scars.

\section{METHODS}

\section{Subject Inclusion and Exclusion Criteria}

Forty-two healthy patients of either sex, aged 18-65 years, who consented to enroll in this study were included. Eligible subjects had elevated scars resulting from surgery, cuts, laser procedure, or burns, and/or wounds where the scar age was no more than 120 days (new scars) and located in an area easily accessible for clinical evaluation. Patients with known hypersensitivity or allergy to silicone or any of the ingredients of the treatment; patients who were pregnant or who planned to become pregnant during the study duration; patients who had a medical condition that would prevent normal healing such as diabetes, peripheral vascular disease, peripheral neuropathy, cancer, rheumatological disease, or lupus; patients with scars with an open wound component; and patients using medication(s) and/ or cosmetic(s) likely to interfere with study results were all excluded from the study.

\section{Study Design}

This prospective, randomized, double blinded, placebo-controlled clinical trial was designed, recorded, and reported in compliance with the principles of Good Clinical Practice (GCP) guidelines. The study was also conducted in accordance with standard operation procedures, the US and international standards of Good
Clinical Practice (FDA regulations 21 CFR for IND studies and FDA guidance E6), and the Declaration of Helsinki concerning medical research in humans. The study protocol and informed consent form were reviewed and approved by an Institutional Review Board (Allendale Investigational Review Board, Old Lyme, CT, USA).

\section{Sample Preparation}

The treatment samples consisted of copaiba oil in silicone gel; Copaderm (Medisca Inc, Plattsburgh, NY, USA), a personal scar care product containing a proprietary mixture of silicone polymers and refined copaiba oil along with other ingredients. The content of placebo gel was water, potassium sorbate, ethoxy diglycol, and hydroxyethyl cellulose. Both samples were prepared to be similar in terms of appearance and consistency. Copaderm and placebo gel were also placed in identical dispensers, which were then labeled.

\section{Study Participants and Assessment of Scars}

All of the subjects were randomly distributed into two groups. Twenty-one patients for each group received a topical scar formulation consisting of copaiba oil in silicone gel (study group) and a topical hydroxyethyl cellulose gel (control group), twice daily for 84 days. The Manchester Scar Scale (MSS) was recorded at baseline and after 84 days of treatment. The Manchester Scar assessment, described by Beausang et al. [15] in 1998, was used to quantify scar appearance in response to treatment in this clinical study. The scale includes color, contour, distortion, and texture. Each of these parameters is given a score of 1 to 4 , with increasing values indicating higher scar severity. Whether a scar is matte or shiny is also recorded, the former scoring 1 and the latter 2 on the overall scale (Table 1). The overall evaluations were calculated by score averages from the scale and subsequently used for the data analysis.

Photographs were also collected at baseline, 28 days, and 84 days using identical camera 
Table 1 Manchester Scar Scale (MSS)

\begin{tabular}{lllll}
\hline Score & $\mathbf{1}$ & $\mathbf{2}$ & $\mathbf{3}$ & $\mathbf{4}$ \\
\hline Color & Perfect & Slight mismatch & Obvious mismatch & Gross mismatch \\
Matte versus shiny & Matte & Shiny & - & - \\
Contour & Flush with surrounding skin & Slightly proud/indented & Hypertrophic & Keloid \\
Distortion & None & Mild & Moderate & Severe \\
Texture & Normal & Just palpable & Firm & Hard \\
\hline
\end{tabular}

settings, lighting conditions, and patient positioning (Nikon D300, 13.1 million total pixels, 12.3 million effective pixels) to establish "before" and "after" treatment improvements. At the end of the study period, patients completed a final satisfaction questionnaire (Table 2).

\section{Statistical Analysis}

Data analysis was performed using Microsoft Excel 2016 and R i386 3.6.1. Mean changes in parameters within groups were assessed for significance using a paired two-sided $t$ test. Mean difference in the improvement of each parameter between test groups was assessed using a one-sided Welch's $t$ test to account for heteroscedasticity of the sample set. Values for $P<0.05$ were considered statistically significant. Boneferroni correction was not applied to any parametric hypothesis testing.

\section{RESULTS}

\section{Patient Demographic and Clinical Data}

At baseline, the subjects were randomly included into one of the two treatment groups. Of the 42 patients initially enrolled, 10 declined after 84 days of treatment. Thus, a total 32 patients (study group, $n=18$; control group,

Table 2 Patient satisfaction assessment form.

\begin{tabular}{|c|c|}
\hline Product evaluation & Scores \\
\hline 1. Color & Unpleasant (1)...(5) Pleasant \\
\hline 2. Smell & Unpleasant (1)...(5) Pleasant \\
\hline 3. Texture & Very sticky $(1) \ldots(5)$ Not sticky at all \\
\hline 4. Irritation & Very irritating $(1) \ldots$ (5) Not irritating at all \\
\hline 5. Ease of use ${ }^{a}$ & Very difficult $(1) \ldots(5)$ Very easy \\
\hline 6. Speed of drying & Very slow $(1) \ldots(5)$ Very fast \\
\hline 7. Application ${ }^{\mathrm{b}}$ & Very difficult $(1) \ldots(5)$ Very easy \\
\hline 8. Feel on skin & Very unpleasant (1)...(5) Very pleasant \\
\hline 9. Overall evaluation & Very dissatisfied (1)...(5) Very satisfied \\
\hline
\end{tabular}

${ }^{a}$ Ease of use: how easy or difficult was it to release the gel from the dispenser

b Application: how easy or difficult was it to apply and spread the gel onto the scar 
$n=14)$ completed the 84-day treatment period and these subjects reported no clinically significant adverse effects. The statistical analysis showed that there was no statistically significant difference in the distributions of gender and age between the test and control groups. Both groups were also well-balanced for Fitzpatrick skin type, race, and location of the scars. The demographic characteristics of each enrolled group are summarized in Table 3.

\section{Clinical Assessment with MSS}

The median total MSS scores at each parameter, the overall scores, and the score difference between the baseline and at 84 days are presented in Table 4. The copaiba oil in silicone gel group showed a decrease of the mean scores in all parameters over time from day 0 to day 84 . Moreover, the results showed a significant difference with respect to the overall score difference of the MSS between the study and the control groups from the baseline to 84 days $(P=0.02)$. Although there was no significant improvement in matte versus shiny for the study group $(P=0.16)$, this did not affect the relevant reduction $(-3.0)$ of the overall scores at the end of the study compared to the baseline. The results also showed that $100 \%$ of the patients with copaiba oil in silicone gel achieved improvement of their scars in the Manchester overall score at 84 days compared to baseline. On the other hand, there were no significant changes in color, matte versus shiny, distortion, texture, and overall scores $(P=0.10$, $P=0.34, P=0.44, \quad P=0.44$, and $P=0.06$, respectively) at 84 days compared to baseline for the control group, and the matte versus shiny score was slightly worse $(+0.08)$ after 84 days using placebo gel.

\section{Before and After Pictures}

Overall, a visible scar reduction was observed with the use of copaiba oil in silicone gel over time. Before and after photographs of scars of some of the study group patients are shown in Figs. 1, 2 and 3.

\section{Patient Final Evaluation}

Overall patient satisfaction was evaluated at the end of the study and $89 \%$ of subjects $(n=16)$ with copaiba oil in silicone gel rated as being satisfied and very satisfied with the treatment after 84 days. Eighty-three percent of the patients $(n=15)$ would recommend this gel after completion of the clinical trial.

\section{DISCUSSION}

Abnormal scarring, including hypertrophic and keloid scars, is a common inflammatory condition that drives an excessive proliferation of dermal tissue after burns, trauma, and surgical treatment [16]. Silicone gels are commonly used in the topical treatment and prevention of abnormal scars and they possess numerous skinfriendly properties such as biocompatibility, atraumatic removal, extended wear time, repositionability, resistant to microbial growth, and hydrophobicity [17].

Several mechanisms have been proposed as possible modes of action for silicone ingredients. These hypotheses include increased temperature or oxygen tension, inhibitory effect on fibroblast growth, wound hydration, polarization of scar tissue, and modulation of growth factors [18-20]. Clinical evidence supported the use of silicone gel preparations as first-line therapy for excessive scars [21]. Medhi et al. [22] in their study reported differences in response to silicone gel among 36 patients. Decrease in pigmentation, pliability, vascularity, and height was observed after 3 months of using silicone gel on postoperative scars. In the study performed by Chittoria et al. [23] comparing the effect of silicone gel in prevention of hypertrophic scar development in donor site scars showed a significant reduction in overall scores and individual parameters such as vascularity, pigmentation, pliability, and height after 8 weeks of treatment compared to the placebo group.

In recent studies, application of gels combined with natural ingredients have also advanced as one of various efficient nonoperative scar therapies based on various scientific 
Table 3 Demographic data of the patients $(n=42)$

\begin{tabular}{|c|c|c|}
\hline & Study group $(n=21)$ & Control group $(n=21)$ \\
\hline \multicolumn{3}{|l|}{ Gender } \\
\hline Female & 14 & 14 \\
\hline Male & 7 & 7 \\
\hline Age $($ mean $\pm S D)$ & $44.23 \pm 15.10$ & $49.13 \pm 11.56$ \\
\hline \multicolumn{3}{|l|}{ Fitzpatrick skin type } \\
\hline I & 0 & 1 \\
\hline II & 9 & 8 \\
\hline III & 7 & 10 \\
\hline IV & 5 & 2 \\
\hline $\mathrm{V}$ & - & - \\
\hline VI & - & - \\
\hline \multicolumn{3}{|l|}{ Race } \\
\hline Caucasian & 11 & 14 \\
\hline Black & 0 & 1 \\
\hline Hispanic/Latino & 10 & 06 \\
\hline \multicolumn{3}{|l|}{ Location } \\
\hline Breast & 3 & 1 \\
\hline Chest & 3 & 3 \\
\hline Lip & 1 & 0 \\
\hline Back & 2 & 7 \\
\hline Neck & 1 & 0 \\
\hline Head & 2 & 1 \\
\hline Forearm & 1 & 2 \\
\hline Chin & 1 & 0 \\
\hline Abdomen & 1 & 3 \\
\hline Shoulder & 1 & 2 \\
\hline Knee & 0 & 1 \\
\hline Thigh & 2 & 1 \\
\hline Hand & 1 & 0 \\
\hline Wrist & 1 & 0 \\
\hline Leg & 1 & 0 \\
\hline
\end{tabular}


Table 4 Manchester Scar Scale scores at different time points: mean values \pm standard deviation of mean, overall scores, and score differences from the baseline

\begin{tabular}{lllllll}
\hline & Color & $\begin{array}{l}\text { Matte/ } \\
\text { shiny }\end{array}$ & Contour & Distortion & Texture & Total score \\
\hline Study group & & & & & & \\
Mean scores at baseline & $3.22 \pm 0.41$ & $1.11 \pm 0.31$ & $2.94 \pm 0.23$ & $2.83 \pm 0.50$ & $2.83 \pm 0.60$ & $12.94 \pm 1.31$ \\
Mean scores at 84 days & $2.50 \pm 0.50$ & $1.00 \pm 0.00$ & $2.44 \pm 0.89$ & $2.00 \pm 0.66$ & $2.00 \pm 0.58$ & $9.94 \pm 2.12$ \\
Score difference baseline/84 day & -0.72 & -0.11 & -0.50 & -0.83 & -0.83 & -3.00 \\
Mean change* & $<\mathbf{0 . 0 5}$ & $>0.05$ & $<\mathbf{0 . 0 5}$ & $<\mathbf{0 . 0 5}$ & $<\mathbf{0 . 0 5}$ & $<\mathbf{0 . 0 5}$ \\
Control group & & & & & & \\
Mean scores at baseline & $3.00 \pm 0.47$ & $1.00 \pm 0.00$ & $2.77 \pm 0.42$ & $2.23 \pm 0.42$ & $2.30 \pm 0.46$ & $11.23 \pm 1.12$ \\
Mean scores at 84 days & $2.5 \pm 0.49$ & $1.08 \pm 0.25$ & $2.08 \pm 0.82$ & $2.08 \pm 0.61$ & $2.15 \pm 0.53$ & $9.85 \pm 2.06$ \\
Score difference baseline/84 day & -0.38 & 0.08 & -0.69 & -0.15 & -0.15 & -1.38 \\
Mean change* & $>0.05$ & $>0.05$ & $<\mathbf{0 . 0 5}$ & $>0.05$ & $>0.05$ & $>0.05$ \\
Group comparison* (score & $>0.05$ & $<\mathbf{0 . 0 5}$ & $>0.05$ & $<\mathbf{0 . 0 5}$ & $<\mathbf{0 . 0 5}$ & $<\mathbf{0 . 0 5}$ \\
difference) & & & & & & \\
\hline
\end{tabular}

Mean \pm SD of MSS at baseline and 84 day follow-up. ${ }^{*} P$-value obtained when applying the Student's $t$ test (in bold if statistically significant)

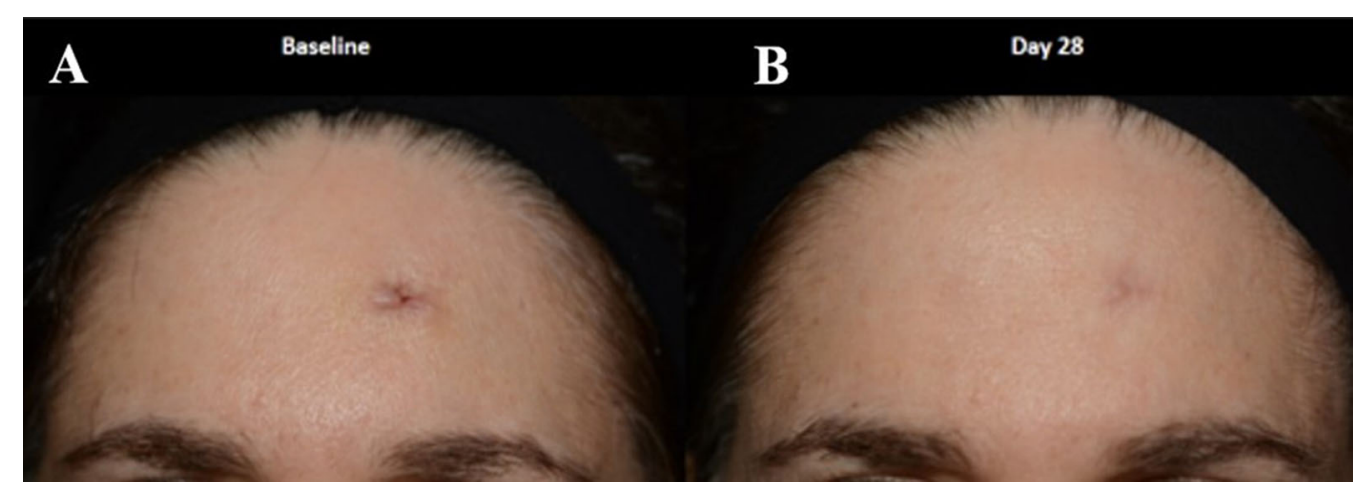

Fig. 1 A Scar on forehead at baseline. B View 28 days after treatment with Copaderm

evidence. Many types of natural products from medicinal plants such as Allium cepa extract, pracaxi oil, Aloe vera, and, Centella asiatica extract have shown activity in scar reduction and show notable advantages in having fewer side effects $[5,24]$. Therefore, in addition to widespread uses of surgical therapy, physiotherapy, and pharmacotherapy, there is an enormous need for developing new plant-based products more efficient than, or synergizing with, the existing ones.

Copaiba oil is widely used in traditional medicine due to its anti-inflammatory, healing, and antiseptic activities, and some authors have shown the effectiveness of copaiba oil in the promotion of wound healing and prevention of abnormal scars $[13,14]$. Even with the typical variation in the chemical composition of this 


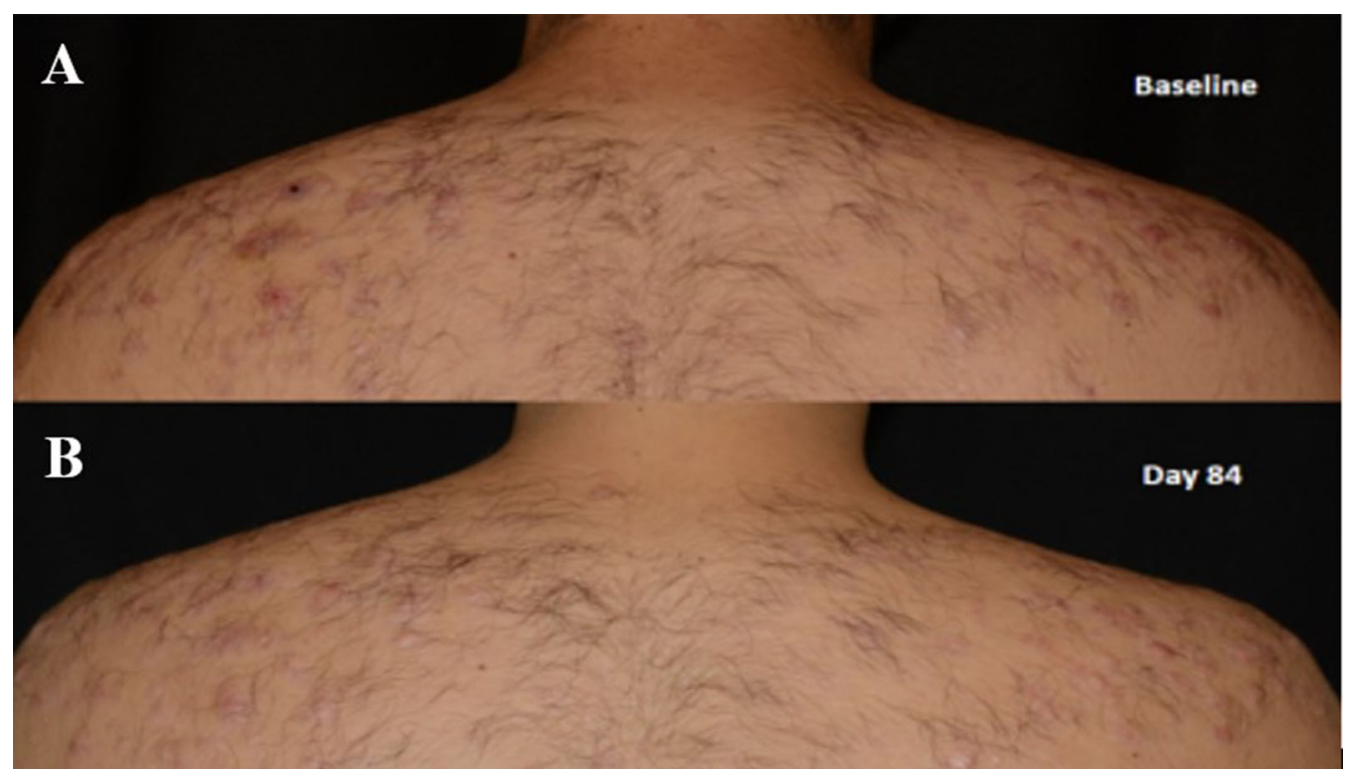

Fig. 2 A Acne scar on the back at baseline. B View 84 days after treatment with Copaderm

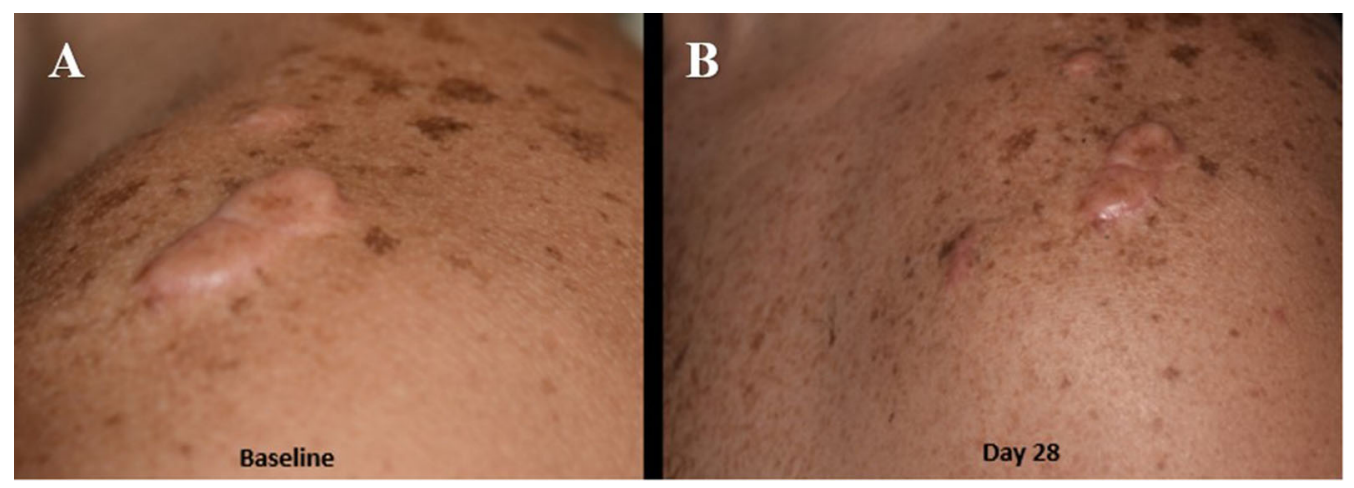

Fig. 3 A Keloid on the left shoulder at baseline. B View 28 days after treatment with Copaderm

oil, the sesquiterpene $\beta$-caryophyllene is the major constituent. This compound represents about $40 \%$ of copaiba oil composition and it has been mentioned in literature as a powerful antiinflammatory, local anesthetic, and anti-microbial agent $[25,26]$. Studies show that prolonged inflammation may play a role in excessive scar formation and, as uncontrolled and chronic inflammation of the dermis produces abnormal scars, the use of anti-inflammatory agents can promote faster wound healing with beneficial effects on scar formation $[16,27]$. Teixeira et al. [28] demonstrated that copaiba oil resin reduced chronic inflammatory infiltrate and inhibited macrophage activity in an in vivo test using rat's tongues. Although the mechanism underlying the beneficial esthetic effect of copaiba oil on scar appearance is unknown, there is strong evidence that the sesquiterpenes constituents of copaiba oil may reduce scar inflammation, promote progression to the proliferative and remodeling phases, and finally reduce the scar appearance [29].

In face of the benefits from silicone ingredients in scar reduction and the worldwide increase of use of natural products in healing, this clinical trial was the first to demonstrate the effectiveness of topical copaiba oil in siliconebased gel (Copaderm) for the prevention and improvement in the appearance of various scar 
types, including hypertrophic, acne and keloid scars. The study compared two groups at 84 days and each group from the baseline to 84 days, during which time all participants were instructed to apply copaiba oil in silicone-based gel or a placebo gel on their scars.

The results demonstrated that the application of copaiba oil in silicone-based gel two times per day achieved beneficial improvement in appearance of new scars after 84 days when compared with a placebo gel. Characteristics of color, contour, distortion, and texture of the scars showed significant score reduction $(-0.72$, $-0.5,-0.83$, and -0.83 , respectively) from the baseline to 84 days, as well as a significant difference $(P<0.05)$ between study and control groups overall scores in the Manchester Scar Scale.

Other authors have also gone further investigating the use of silicone gel and have found similar benefits in the combination of silicone derivatives plus plant-based ingredients in the treatment and reduction of scars. Jenwitheesuk et al. [30] observed improvement in pain, itch, and pigmentation of scars after using a combination of a silicone gel and onion extract for hypertrophic scars over a treatment period of 12 weeks in comparison with a placebo group. In another clinical trial conducted by Nestor et al. [5], a silicone gel containing pracaxi oil was effective as an onion extract gel for improving the appearance of hypertrophic postsurgical scars after 12 weeks of treatment.

Our findings support the hypothesis that copaiba oil in silicone-derivative gel (Copaderm) can improve the scarring outcome of abnormal scars and it provides a beneficial effect on the scar appearance of the subjects. In addition, the majority of patients in the study group (89\%) responded that they were satisfied using the patient self-assessment that included allergic reaction, product appearance, overall comfort, speed of drying, application, feel on skin, and overall satisfaction. It is compelling to note that, based on this satisfaction assessment, $83 \%$ of these patients would recommend Copaderm after 84 days of treatment. The before and after photograph comparisons combined with the patients' assessment also provide good evidence that the application of copaiba oil in silicone-based gel for 84 days ameliorated the appearance of different type of scars in the study group.

To our knowledge, this prospective study represents the first evaluation of the scar reduction efficacy following copaiba oil in silicone-based gel application. Despite the fact that this study has reported promising results, it has some limitations. Most important is the small number of subjects for each group $(n=21)$ and the fact that only Manchester Scar Scale has been used to assess the scar parameters during the treatment. Although this scale has been validated and is commonly used for scar care products evaluation, it is still subjective. Because this study population was relatively small, it would be advisable to study the effectiveness of topical copaiba oil in silicone-based gel on a larger scale. A comparative study with silicone gel and other plant-based scar reduction products would be another apt comparison.

\section{CONCLUSION}

In conclusion, this study demonstrates that copaiba oil in silicone-based gel is able obtain significant improvement in color, contour, distortion, and texture for different types of scar through the Manchester Scar Scale analysis. These findings contribute to reduce the abnormal scar formation during the healing process. There were no side effects found with Copaderm, and patient overall evaluation and compliance were satisfactory. Further research is needed to identify the processes responsible for the development of these beneficial improvements more precisely.

\section{ACKNOWLEDGEMENTS}

Funding. Sponsorship for this study and article processing charges were funded by Medisca Pharmaceutique Inc. (Montreal, QC, Canada). All authors had full access to all data in this study and take complete responsibility 
for the integrity of the data and the accuracy of the data analysis.

Medical Writing and Other Assistance. The authors are grateful to Alexander Bullis (Medisca Pharmaceutique Inc.) for assistance with statistical analysis. We also thank all subjects who participated in this study.

Authorship. All named authors meet the International Committee of Medical Journal Editors criteria for authorship for this article, take responsibility for the integrity of the work as a whole, and have given their approval for this version to be published.

Author Contributions. All authors made substantial contributions to the conception, design, data analysis and interpretation, as well as critical revision of the manuscript and providing final approval of the manuscript to be published. J. Waibel also performed the data collection. R. Lupatini was also involved in the manuscript drafting.

Disclosures. Rodrigo Lupatini, Harshad Patel, Erica Cull, and Raman Sidhuare employees of Medisca Pharmaceutique Inc, which funded this study. Jill Waibel, MD, a board certified dermatologist and Owner and Director of Miami Dermatology and Laser Research Institute, performed the study and received speaking and research support from Medisca Pharmaceutique Inc.

Compliance with Ethics Guidelines. The study protocol and informed consent form were reviewed and approved by an Institutional Review Board (Allendale Investigational Review Board, Old Lyme, CT). The study was conducted in accordance with the ethical principles of the Declaration of Helsinki, the USA and international standards of Good Clinical Practice (FDA regulations 21 CFR for IND studies and FDA guidance E6).

Data Availability. The datasets generated during and/or analyzed during the current study are available from the corresponding author on reasonable request.
Open Access. This article is licensed under a Creative Commons Attribution-NonCommercial 4.0 International License, which permits any non-commercial use, sharing, adaptation, distribution and reproduction in any medium or format, as long as you give appropriate credit to the original author(s) and the source, provide a link to the Creative Commons licence, and indicate if changes were made. The images or other third party material in this article are included in the article's Creative Commons licence, unless indicated otherwise in a credit line to the material. If material is not included in the article's Creative Commons licence and your intended use is not permitted by statutory regulation or exceeds the permitted use, you will need to obtain permission directly from the copyright holder. To view a copy of this licence, visit http://creativecommons.org/licenses/by$\mathrm{nc} / 4.0 /$.

\section{REFERENCES}

1. Bayat A, McGrouther DA, Ferguson MW. Clinical review-skin scarring. BMJ. 2003;326:88-92.

2. McGoldrick RB, Sawyer A, Davis CR, et al. Lasers and ancillary treatment for scar management: personal experience over two decades and contextual review of the literature. Part I: burn scars. SB\&H. 2016;2:1-7.

3. Monstrey S, Middelkoop E, Vranckx JJ, et al. Updated scar management practical guidelines: non-invasive and invasive measures. J Plast Reconstr Aesthet Surg. 2014;67:1017-25.

4. Marshall $\mathrm{CD}, \mathrm{Hu} \mathrm{MS}$, Leavitt $\mathrm{T}$, et al. Cutaneous scarring: basic science, current treatment, and future directions. Adv Wound Care. 2016;7(2): $29-45$.

5. Nestor MS, Berman B, Jones JL. Comparison of safety and efficacy of a silicone-based gel containing pracaxi oil (Pentaclethra macroloba) versus a silicon-based gel containing cepalin onion extract for the treatment of post-surgical hypertrophic scars. Skin. 2018;2(6):380-8.

6. Draelos ZD, Baumann L, Fleischer AB, et al. A new proprietary onion extract gel improves the appearance of new scars: a randomized, controlled, blinded-investigator study. J Clin Aesthet Dermatol. 2012;5(6):18-24. 
7. Sidgwick GP, McGeorge D, Bayat A. A comprehensive evidence-based review on the role of topicals and dressings in the management of skin scarring. Arch Dermatol Res. 2015;307:461-77.

8. Ricardo LM, Dias BM, Mügge FLB, et al. Evidence of traditionality of Brazilian medicinal plants: the case studies of Stryphnodendron adstringens (Mart.) Coville (barbatimão) barks and Copaifera ssp. (copaíba) oleoresin in wound healing. J Ethnopharmacol. 2018;12(219):319-36.

9. Albuquerque KCO, Veiga ASS, Silva JVS, et al. Brazilian Amazon traditional medicine and the treatment of difficult to heal leishmaniasis wound with Copaifera. Evid Based Complement Altern Med. 2017;2017:1-9.

10. Amorim JL, Figueiredo JB, Amaral ACF, et al. Wound healing properties of Copaifera paupera in diabetic mice. PLoS One. 2017;12(10):1-14.

11. Martini CAN, Scapini JGS, Collaço LM, et al. Comparative analysis of the effects of Copaifera multijuga oil-resin and nitrofurazone in the cutaneous wound healing process. Rev Col Bras Cir. 2016;43(6): $445-51$.

12. Estevão LRM, Medeiros JP, Baratella-Evêncio L, et al. Effects of the topical administration of copaiba oil ointment (Copaifera langsdorffii) in skin flaps viability of rats. Acta Cir Bras. 2013;28(12): 863-9.

13. Trindade R, Silva JK, Setzer WN. Copaifera of the neotropics: a review of the phytochemistry and pharmacology. Int J Mol Sci. 2018;19(5):1511.

14. Guimarães ALA, Cunha EA, Matias FO, et al. Antimicrobial activity of copaiba (Copaifera officinalis) and pracaxi (Pentaclethra macroloba) oils against Staphylococcus Aureus: importance in compounding for wound care. Int J Pharm Compd. 2016;20(1):58-62.

15. Beausang E, Floyd H, Dunn KW, et al. A new quantitative scale for clinical scar assessment. Plast Reconstr Surg. 1998;102(6):1954-61.

16. Ogawa R. Keloid and hypertrophic scars are the result of chronic inflammation in the reticular dermis. Int J Mol Sci. 2017;18(3):606.

17. Mehta M, Branford OA, Rolfe KJ. The evidence for natural therapeutics as potential anti-scarring agents in burn-related scarring. Burns Trauma. 2016;4:15.

18. Song T, Kim KH, Lee KW. Randomized comparison of silicone gel and onion extract gel for post-surgical scars. J Obstet Gynaecol. 2018;38(5):702-7.
19. Kim SM, Choi JS, Lee JH, et al. Prevention of postsurgical scars: comparison of efficacy and convenience between silicone gel sheet and topical silicone gel. J Korean Med Sci. 2014;29:S249-253.

20. Karagoz H, Yuksel F, Ulkur E, et al. Comparison of efficacy of silicone gel, silicone gel sheeting, and topical onion extract including heparin and allantoin for the treatment of postburn hypertrophic scars. Burns. 2009;2009(35):1097-103.

21. Gold MH, McGuire M, Mustoe A, et al. Updated international clinical recommendations on scar management: part 2-algorithms for scar prevention and treatment. Dermatol Surg. 2014;40:825-31.

22. Medhi B, Sewal RK. Efficacy and safety of an advanced formula silicone gel for prevention of post-operative scars. Dermatol Ther. 2013;3:157-67.

23. Chittoria RK, Padi TR. A prospective, randomized, placebo controlled, double blind study of silicone gel in prevention of hypertrophic scar at donor site of skin grafting. J Cutan Aesthet Surg. 2013;6(1): $12-6$.

24. Chuangsuwanich A, Jongjamfa K. The efficacy of combined herbal extracts gel preparation in the prevention of postsurgical hypertrophic scar formation. Dermatol Ther. 2014;4:187-95.

25. Leandro L, Vargas FS, Barbosa PCS, et al. Chemistry and biological activities of terpenoids from copaiba (Copaifera spp.) oleoresins. Molecules. 2012;17: 3866-89.

26. Veiga-Junior VF, Rosas EC, Carvalho MV, et al. Chemical composition and anti-inflammatory activity of copaiba oils from Copaifera cearensis Huber ex Ducke, Copaifera reticulate Ducke and Copaifera multijuga Hayne-a comparative study. J Ethnopharmacol. 2007;112:248-54.

27. Jeong W, Yang CE, Roh TS, et al. Scar prevention and enhanced wound healing induced by polydeoxyribonucleotide in a rat incisional woundhealing model. Int J Mol Sci. 2017;18(8):1698.

28. Teixeira FB, Silva RB, Lameira OA, et al. Copaiba oilresin (Copaifera reticulata Ducke) modulates the inflammation in a model injury to rats' tongues. BMC Complement Altern Med. 2017;14:313.

29. Koyama S, Purk A, Kaur M, et al. Beta-caryophyllene enhances wound healing through multiple routes. PLoS One. 2019;14(12):e0216104.

30. Jenwitheesuk K, Surakunprapha P, Jenwitheesuk K, et al. Role of silicone derivative plus onion extract gel in presternal hypertrophic scar protection: a prospective randomized, double blinded, controlled trial. Int Wound J. 2012;9(4):397-402. 